\title{
EVALUATION OF EFFECT OF MELATONIN ON HEMATOLOGICAL PARAMETERS IN PATIENTS OF PERIODONTITIS
}

\author{
Anagha Marawar ${ }^{1}$, Pramod Marawar ${ }^{2}$, Nandal $\mathrm{DH}^{3}$, Rahul Kunkulol ${ }^{4}$, Sandeep Narwane ${ }^{1}$ \\ ${ }^{1}$ Associate Professor, ${ }^{3}$ Professor and Head, ${ }^{4}$ Professor, Department of Pharmacology, \\ Rural Medical College, PIMS, Loni, Ahmednagar, Maharashtra,
}

${ }^{2}$ Former Professor and Head, Department of Periodontics, Rural Dental College, Loni, Ahmednagar, Maharashtra.

\section{ABSTRACT}

Introduction: Considering the immunity enhancing property of melatonin, a study on the evaluation of the effect of melatonin on the hematological parameters in patients suffering from Periodontitis. Methods: This study was conducted in the Department of Periodontics, Rural Dental College, Loni. Patients of chronic Periodontitis, of age between 18 to 65 years of either gender ready to give informed consent to participate in the study were included. Postoperative patients, patients having night duties, drivers and those using heavy machinery, pregnant women, lactating mothers, patients with any clinically significant systemic disease and patients on any other drugs were excluded from the study. Patients were divided into two Groups. Group B received scaling and root planning (SRP) and melatonin 3 mg per day were compared to Group A which received SRP only. The Total Leukocyte count, Differential Leukocyte count and Erythrocyte sedimentation rate of each patient was studied at a baseline, $1^{\text {st }}$ (30 days) visit, $2^{\text {nd }}(60$ days) visit and $3^{\text {rd }}$ (90 days) visit. Results: Both the groups consisted of 80 subjects each. Group A consisted of $71.25 \%$ male and $28.75 \%$ female patients. There were $56.25 \%$ male and $43.75 \%$ female patients in Group B. With respect to visit 3, the TLC was statistically lower in Group B. The neutrophil count of Group B was significantly lower during visit 3 as compared to Group A. The lymphocyte count of Group B was significantly lower than that of Group A during the visit 1 , and also significantly higher during visit 3 on comparison with Group A. There was no statistically significant difference in the groups with respect to eosinophil and basophil count. The Monocyte count of Group B was statistically lower when compared to that of Group A. There was no statistically significant difference between ESR of Group A \& Group B. Conclusions: It can be concluded that melatonin has a positive effect on TLC and differential count of patients of periodontitis, conferring a new facet to the management of periodontitis and an attempt to impede the disease progression.

Keywords: Melatonin; Hematological parameters; Periodontitis; Total Leukocyte count; Differential Leukocyte count; Erythrocyte sedimentation rate; Scaling and Root Planning.

\section{INTRODUCTION}

Periodontal disease affects about $10-15 \%$ of the population worldwide [1]. Periodontal disease is now known to be a primarily a systemic disease that simply manifest in the oral cavity. More that $90 \%$ of systemic diseases reveal signs and symptoms in mouth [2].

At present, periodontitis, its destructive phase, is considered to be initiated and perpetuated by a small group of predominantly gram-negative, anaerobic, or microaerophilic bacteria that colonize the subgingival area. There is a delicate balance between inflammatory and immune cells hypofunction where unchecked pathogens cause direct tissue damage and hyperfunction, where hosts defence cell products elaborated in all effort to eliminate pathogens inadvertently cause substantial collateral host tissue damage [3]. Tissue infiltration by polymorphonuclear leukocytes and monocytes and subsequent phagocytosis, features a burst of cyanide insensitive (i.e., non-mitochondrial) $\mathrm{O}_{2}$ consumption, which

\begin{tabular}{ll}
\hline DOI: $10.31878 /$ ijcbr.2019.52.10 \\
\hline
\end{tabular}

may be 10 or 20 times that of resting consumption [4].

Until now, primary clinical weapons against periodontal disease have been scaling and root planning (SRP), antibiotics and surgery. Clinical research says that SRP is ineffective up to $40 \%$ of time and when it does work, SRP reduces pocket depths by a little over $1 \mathrm{~mm}$ on an average. Also, SRP is topical and it does nothing to decrease the systemic nature of periodontitis. Antioxidants, if given, can act systemically to support the body's natural immune system.

\begin{abstract}
Melatonin is a ubiquitous natural neurotransmitter like compound produced primarily by pineal gland [5]. The role of endogenous melatonin in circadian rhythm disturbances and sleep disorders is well established [6]. Subsequently, melatonin was shown to have significantly broader action including oncostatic effects, immune system stimulation and anti-inflammatory functions. Furthermore, many studies have proved that salivary, melatonin level varies according to the degree of periodontal disease indicating that salivary melatonin may act to protect the body from external body insults. Therefore, melatonin supplementation, i.e., synthetic version of hormone melatonin may be potentially valuable in the treatment of periodontal diseases [7].
\end{abstract}

Correspondence: Sandeep Narwane, Associate Professor, Department of Pharmacology, Rural Medical College, PIMS, Loni, Ahmednagar, Maharashtra Email: drsandeepnarwane1984@gmail.com 
Considering the above-mentioned functions of melatonin, this study was designed to evaluate the ability of melatonin supplementation to reduce the periodontal inflammation.

\section{MATERIAL AND METHODOLOGY}

Study design: The present study was a Prospective longitudinal study

Ethics approval: The study commenced after the approval of Institutional ethical committee Pravara Institute of Medical Sciences. Patients satisfying the inclusion and exclusion criteria were included in the study after taking their written informed consent.

Research place: Collaboration with the Department of Periodontics \& Oral Implantology, Rural Dental College and Department of Biochemistry, Rural Medical College \& Hospital, Loni.

\section{Study period: One year}

Study population: The subjects enrolled for this study were selected from the out-patient Department of Periodontics, Rural Dental College, Loni

Inclusion criteria: Patients of chronic periodontitis, of age between 18 to 65 years of either gender ready to give informed consent to participate in the study were included.

Exclusion criteria: Postoperative patients, patients having night duties, drivers and those using heavy machinery, pregnant women, lactating mothers, patients with any clinically significant systemic disease and patients on any other drugs were excluded from the study.

Grouping: Depending on the treatment received, the patients were divided into two groups as Group A included patients who underwent SRP (Scaling and Root Planning) alone, Group B who underwent SRP \& supplemented with tablet melatonin $3 \mathrm{mg}$ daily at night for 4 weeks.

\section{Methodology:}

The study participants visited on day 0 (visit 1 ), day 30 (visit 2), day 60 (visit 3) and day 90 (visit 4). During the baseline visit scaling and root planning was performed in all patients. During these visits the Total leukocyte count (TLC), Differential leukocyte count (DLC) and Erythrocyte sedimentation rate (ESR) were studied.

\section{RESULTS}

Figure 1 shows the age and sex wise distribution of the subjects in the groups under study. Both the groups consisted of 80 subjects each. Group A consisted of $71.25 \%$ male and $28.75 \%$ female patients. There were $56.25 \%$ male and $43.75 \%$ female patients in Group B.

$* \mathrm{P}=0.01$ vs $\mathrm{A}$ ( $\mathrm{Z}$ test for difference between two sample means)

Table No. 1 shows the distribution of values of Total Leukocyte Count (TLC) in both groups at all visits. The TLC fell with each visit in Group A, while it increases during the visit 2 in the Group B. On comparing the groups with respect to TLC, there was no statistically significant difference between the groups with respect to baseline visit and visit 1 . With respect to visit 3 , the TLC was statistically lower in Group B.

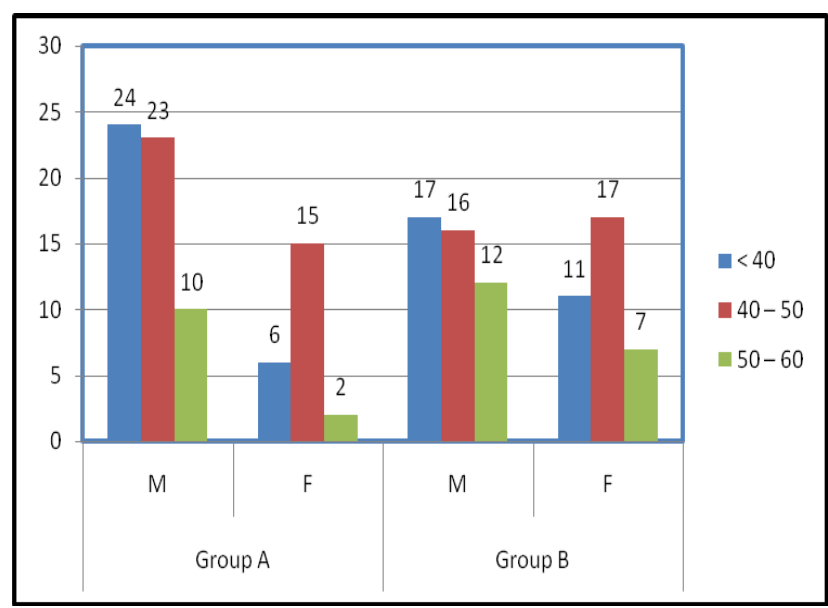

Fig 1: Age and sex wise distribution of the subjects under study

Table 1: Total Leukocyte Count of patients during four visits in groups under study.

\begin{tabular}{|c|c|c|}
\hline $\begin{array}{c}\text { Total Leuko- } \\
\text { cyte Count } \\
\text { (cells/cu mm) }\end{array}$ & Group A & Group B \\
\cline { 2 - 3 } & Mean \pm SD & Mean \pm SD \\
\hline Base line visit & $9117.5 \pm 2103.9$ & $9370 \pm 2278.7$ \\
\hline Visit 1 & $9112.5 \pm 2098.4$ & $8916.2 \pm 1868.1$ \\
\hline Visit 2 $^{\text {sd }}$ & $8886.2 \pm 1783.5$ & $9205.5 \pm 1719.6$ \\
\hline Visit 3 & $8531.6 \pm 1555.4$ & $7593.7 \pm 1493.2^{\text {rd }}$ \\
\hline
\end{tabular}

Table No. 2 shows the distribution of values Neutrophils (N), Lymphocytes (L), Eosinophols (E), Monocytes (M), Basophils (B) count in groups at all visits.

The neutrophil count of Group B was significantly lower during visit 3 as compared to Group A. The lymphocyte count of Group B was significantly lower than that of Group A during the visit 1, and also significantly higher during visit 3 on comparison with Group A. There was no statistically significant difference in the groups with respect to eosinophil and basophil count. The Monocyte count of Group B was statistically lower when compared to that of Group A. All other comparisons were not statistically significant.

Figure 2 shows the distribution of values of Erythrocyte Sedimentation Rate (ESR) in all groups at all visits. There was no statistically significant difference between ESR of Group A when compared with Group B during all visits.

\section{DISCUSSION}

As described in 'Observations', 160 diagnosed patients of periodontitis participated in the study, consisting of 80 patients in each group. The percentage of male patients was higher than their female counterparts in both the groups. 
Table 2: Differential Leukocyte Count of patients during four visits in groups under study.

\begin{tabular}{|c|c|c|}
\hline \multirow{2}{*}{$\begin{array}{l}\text { Differential } \\
\text { Leukocyte } \\
\text { Count }\end{array}$} & Group A & Group B \\
\hline & Mean \pm SD & Mean $\pm \mathrm{SD}$ \\
\hline \multicolumn{3}{|l|}{ Neutrophils (\%) } \\
\hline Base line visit & $74.05 \pm 6.15$ & $74.71 \pm 6.64$ \\
\hline Visit $1^{\text {st }}$ & $73.87 \pm 5.09$ & $75.57 \pm 5.24$ \\
\hline Visit $2^{\text {nd }}$ & $73.97 \pm 5.55$ & $74.29 \pm 4.87$ \\
\hline Visit $3^{\text {rd }}$ & $75.18 \pm 5.79$ & $73.10 \pm 4.17 *$ \\
\hline \multicolumn{3}{|c|}{ Lymphocytes (\%) } \\
\hline Base line visit & $22.70 \pm 4.84$ & $22.30 \pm 5.88$ \\
\hline Visit $1^{\text {st }}$ & $23.50 \pm 4.89$ & $22.30 \pm 5.88^{*}$ \\
\hline Visit $2^{\text {nd }}$ & $22.78 \pm 4.98$ & $21.67 \pm 4.59$ \\
\hline Visit $3^{\text {rd }}$ & $21.62 \pm 5.36$ & $22.86 \pm 4.34 *$ \\
\hline \multicolumn{3}{|l|}{ Eosinophils (\%) } \\
\hline Base line visit & $0.41 \pm 0.84$ & $0.31 \pm 0.68$ \\
\hline Visit $1^{\text {st }}$ & $0.16 \pm 0.43$ & $0.27 \pm 0.74$ \\
\hline Visit $2^{\text {nd }}$ & $0.38 \pm 1.58$ & $0.27 \pm 0.55$ \\
\hline Visit $3^{\text {rd }}$ & $0.22 \pm 0.55$ & $0.35 \pm 0.71$ \\
\hline \multicolumn{3}{|l|}{ Monocytes (\%) } \\
\hline Base line visit & $0.95 \pm 1.04$ & $0.82 \pm 0.97$ \\
\hline Visit $1^{\text {st }}$ & $0.68 \pm 0.72$ & $0.65 \pm 0.85$ \\
\hline Visit $2^{\text {nd }}$ & $0.91 \pm 0.84$ & $0.63 \pm 0.78 *$ \\
\hline Visit $3^{\text {rd }}$ & $1.0 \pm 0.95$ & $0.71 \pm 0.79$ \\
\hline \multicolumn{3}{|l|}{ Basophils (\%) } \\
\hline Base line visit & $1.85 \pm 1.57$ & $1.64 \pm 1.39$ \\
\hline Visit $1^{\text {st }}$ & $1.67 \pm 1.33$ & $1.65 \pm 1.64$ \\
\hline Visit $2^{\text {nd }}$ & $1.95 \pm 1.70$ & $1.80 \pm 1.48$ \\
\hline Visit $3^{\text {rd }}$ & $1.87 \pm 1.80$ & $1.73 \pm 1.35$ \\
\hline
\end{tabular}

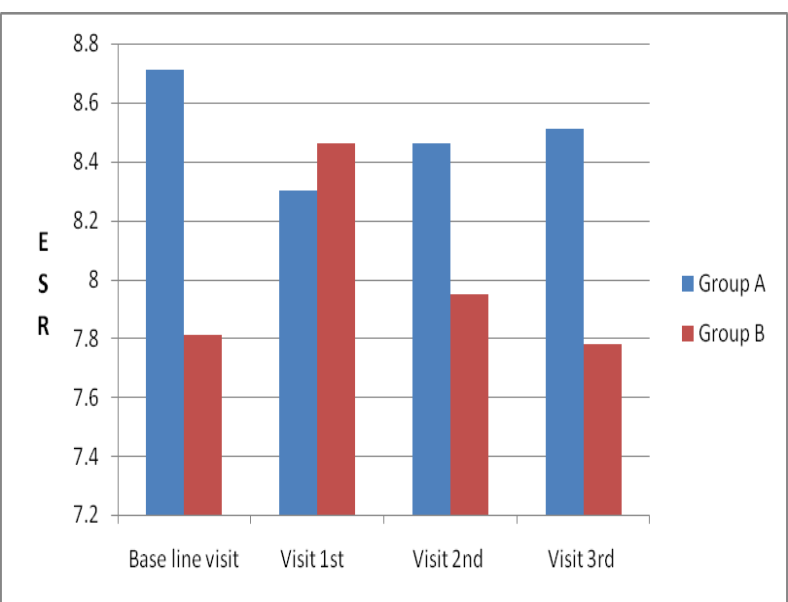

Fig 2: Erythrocyte Sedimentation Rate of patients during four visits in groups under study.

There was a highly significant difference between mean values of TLC when groups were compared at $3^{\text {rd }}$ visit $(p<0.01)$. TLC is considered as one of the inflammatory signs. Thus, these finding could depict that it took time after administration of study drugs to lower the level of TLC. But melatonin was again superior to group A in lowering the levels of TLC from pretreatment to post treatment levels. No comparable study could be found in literature done in humans.

There was a highly significant decrease in the mean values of neutrophils and lymphocytes in group B when compared with group $A$ at $3^{\text {rd }}$ visit $(p<0.01)$. Thus, these findings could suggest that melatonin has a better role in reducing the inflammatory mediators in the body.

Regarding ESR, there was no significant difference between mean values of ESR when compared at all visits $(\mathrm{p}>0.05)$.

In a study by Domple etal [8], the granulocyte count was higher in buffalos of control groups as compared to those treated with subcutaneous Melatonin. A significant increase in total leukocytic count and lymphocyte percentage was found in broiler chicks (Ahmed etal [9], Abozahra et al [10]), rats (Anwar et al [11]), immature chicks (Bernan et al [12]) and squirrels (Rai et al [13]). The findings the animal studies are similar to our study done in humans. While the exact mechanism behind the differential effect is still not known, the postulated mechanisms consist of stimulation of bone marrow (Kuci et al. [14]), lymphatic tissue (Maestroni [15]), reduction in corticosterone hormone (Anwar et al [11]) or protection of bone marrow from damage by free radicals due to its antioxidant effects (Ahmed et al [16])

In recent years, melatonin has been shown to play a fundamental role in neuro-immunomodulation. In vivo studies by Antonio Carrillo-Vico et al [17] show that melatonin exerts immune-enhancing properties by modulating cytokine production.

Melatonin activates several elements of the immune system that reduce tissue destruction during the inflammatory response, either directly by free radical scavenging or indirectly by modulating the action of agents such as cytokines and adhesion molecules, which contribute to the advance of cell damage.

\section{CONCLUSION}

It can be concluded that melatonin has positive effect on TLC and differential count of patients of Periodontitis, conferring a new facet to the management of Periodontitis and an attempt to impede the disease progression. To our knowledge, this is one of the first attempts to examine the influence of melatonin supplementation on periodontal disease. Data from this study suggested a positive result in this regard.

Conflict of Interest: Declared none

\section{REFERENCES}

[1] Petersen PE, Ogawa H. Strengthening the prevention of periodontal disease: the WHO approach. J Periodontol 2005;76:2187-93

[2] Chronic periodontitis, In: Newman, Takei, Klokkevold and Carranza, eds. Carranza's Clinical Periodontology. $10^{\text {th }}$ ed. Elsevier publications, New Delhi, 2007: 494-9

[3] Chapple ILC. Role of free radicals \& antioxidants in the pathogenesis of the inflammatory periodontal diseases. J Clin Pathol 1996; 49: M247- 55

[4] Battino M, Bullon P, Wilson M and Newman H. Oxidative injury and inflammatory periodontal 
diseases. The challenge of antioxidants to free radicals and reactive oxygen species. Crit Rev Oral Biol Med 1999; 10(4): 458-76

[5] Malhotra S, Sawhney G, Pandhi P. The therapeutic potential of Melatonin: A review of the Science. MedGenMed. 2004;6(2):46.

[6] Kantarci A, Thomas E and Van Dyke. Resolution of inflammation in Periodontitis. J Periodontal, November 2005; 76 (11 suppl): 2168-74

[7] Russel RJ, Corneiro RC and Oh CS. Melatonin in relation to cellular antioxidative defence mechanisms. Horm Metab Res, Aug 1997; 29 (8): 26372

[8] Domple VD. Effect of Melatonin Supplementation on Haematological Parameters in Buffalo Calves under Summer Stress. International Journal of Livestock Research 2017; 7(5): 266-74

[9] Ahmed HH. Effect of Melatonin on Some Hematological Parameters and Immune Status of Broiler Chicks. Journal of Agricultural Science 2011;3 (2):243-54

[10] Abozahra AA, El-sayed M, Elshazly KA, Saad MF. The influence of melatonin on the immune response to IBD vaccination in broilers. J. Zagazig Vet., Med. 4th Vet. Med. Zag. Congress, 1998;600 $-8$

[11] Anwar MM, Mahfouz HA, Sayed AS. Potential protective effects of melatonin on bone marrow of rats exposed to cytotoxic drugs. Com. Biochem. Physiol. A. Mol. Integr. Physiol. 1998;199 (2):499 $-501$

[12] Brennan CP, Hendricks GL, El-Sheikh TM, Mashaly MM. Melatonin and enhancement of immune responses in immature male chickens. Poult. Sci.,2002;18: 371-5

[13] Rai S, Haldar C, Singh R. Modulation of immunity in young-adult and aged squirrel, Funnambulus pennant by melatonin and parachlorophenylalanin. Immunity and aging. 2009;6:5.

[14] Kuci S, Becker J, Veit G, Haldar C, Handgretinger $\mathrm{R}$, Attanasino, A. Circadian variations in the immunomodulatory role of the pineal gland. Neuroendocrinol. Lett., 1987;9(5):287

[15] Maestroni GJ, Conti A. Melatonin in relation to the immune system. In. Yu, H. S., Retier, R. J. (Eds). Melatonin biosynthesis, physiological effect and clinical applications, Chapter 11. New York: CRC Press, 1983;289-309

[16] Ahmed HH, Essawy, GS, Salem HA, Abdel Daim MA. Melatonin has a strong antioxidant activity and improves liver and kidney functions in broiler chicks. Egypt. J. Basic and Appl. Physiol. 2005;4 (1):77-92

[17] Carrillo-Vico A, Calvo JR., Abreu P, Lardone PJ, García-Mauriño S, Russel RJ, et al. Evidence of melatonin synthesis by human lymphocytes and its physiological significance: Possible role as intra- crine, autocrine, and/or paracrine substance. The FASEB Journal Express Article January 2004; 8 (10): 1096 